\title{
Development of Rainfall Intensity-Duration-Frequency (IDF) Curve for Abuja, Nigeria
}

\author{
M. A. Ahmed ${ }^{\mathrm{a}, *}$, A. T. Olowosulu ${ }^{\mathrm{a}}$, B. K. Adeogun ${ }^{\mathrm{b}}$, A. A. Murana ${ }^{\mathrm{a}}$, H. A. \\ Ahmed $^{\mathrm{a}, * *}$ I. M. Sanni ${ }^{\mathrm{b}}$ \\ ${ }^{a}$ Department of Civil Engineering, Ahmadu Bello University, Zaria, Kaduna State, NIGERIA. \\ ${ }^{b}$ Department of Water Resources Engineering, Ahmadu Bello University, Zaria, Kaduna State, NIGERIA.
}

\begin{abstract}
Urban flooding is a major social and economic problem of any nation. The social implication is attributed to loss of lives and property, unwanted displacement and emotional disturbance attached. While that of economic problem is the cost of mitigation of flood and the aftermath solution. Thus, storm water drainage is part of essential modern city infrastructure. The need for proper analysis and design of drainages and other road water facilities cannot be overemphasized. To achieve this, critical analysis of available rainfall data, which is a key input, is required. A 35 years daily rainfall data were obtained from NIMET, from which the analysis was carried out using frequency method. The output generated are presented in graphical forms and model.Ultimately, an IDF curve generated, depicts Abuja rainfall pattern from which a 3-parameter model equation, $I=37 T_{r}^{0.2}(t+0.1)^{-0.9}$ was formulated. This is site or location specific. The curve and/or the formulated model can be adopted to determine rainfall intensity of Abuja city if the rainfall duration and return period are predictable.
\end{abstract}

Keywords: IDF, rainfall, drainage, rainfall intensity, rainfall duration, return period

\section{INTRODUCTION}

Rainfall models can be expressed mathematically to represent a relationship between intensity, duration and frequency (IDF). An IDF model provides the basic probabilistic rainfall information for runoff estimation and establishes a statistical basis for design, using the return period as the measure of frequency of failure [1].

An IDF curve is a tool that characterises an area rainfall pattern. This can be analysed to predict future rainfall/storm occurrence and thus used against the design of engineering facilities of the area [2].

Empirically, these analyses are based on statistical formulation and assumptions that help in (with various factors considered) developing a mathematical model, as a representation of the different variables, namely rainfall intensity duration and frequency, and for the design of drainage facilities of the area.

The development of rainfall model requires long term rainfall data [3]; and only few meteorolog-

\footnotetext{
${ }^{*}$ Corresponding author (Tel: +234 (0)812 901 1503)

${ }^{* *}$ Late

Email addresses: tabanson@gmail.com (M. A. Ahmed), atolowosulu@gmail.com (A. T. Olowosulu), adeogunbk@gmail.com (B. K. Adeogun), fatinoyi2007@yahoo.co.uk (A. A. Murana), ashara.hadi@gmail.com (H. A. Ahmed), engrmsaniismail@gmail.com (I. M. Sanni)
}

ical stations in Nigeria (being a developing country) have this record, spanning over 30 years. This poses a huge challenge for hydrologists and Engineers in the design of water resources structures $[3,4]$.

The design of water resources structure i.e. drainages, culverts, etc, requires an Engineer to carry out a thorough analysis on the available rainfall data, using a reliable statistical method; this involves checking the consistency of the data before applying suitable and reliable method to determine rainfall intensity (or depth), which is a key input on the design $[2,5]$.

In this research, IDF curve of Abuja city and a mathematical model was developed from 35 years rainfall data (1982-2017) obtained from NIMET, using frequency analysis method.

Abuja (Federal Capital Territory, FCT) covers a total land area of $7315 \mathrm{sq} \mathrm{km}$, approximately. It is bordered by Kaduna State from the North, Niger State from the West; Nasarawa State from East and South-East and Kogi State on its SouthWest. It falls within the latitude of $7.45^{\circ}$ and $7.39^{\circ}$. Abuja falls within the Guinea Forest Savannah, mosaic region of West Africa sub-region. Rainfall in the FCT reflects its location on the windward side of the Jos Plateau and the zone of rising air masses with the city receiving frequent rainfall during the rainy season from April to October every year [6].

According to 2006 census, Abuja had a popula- 


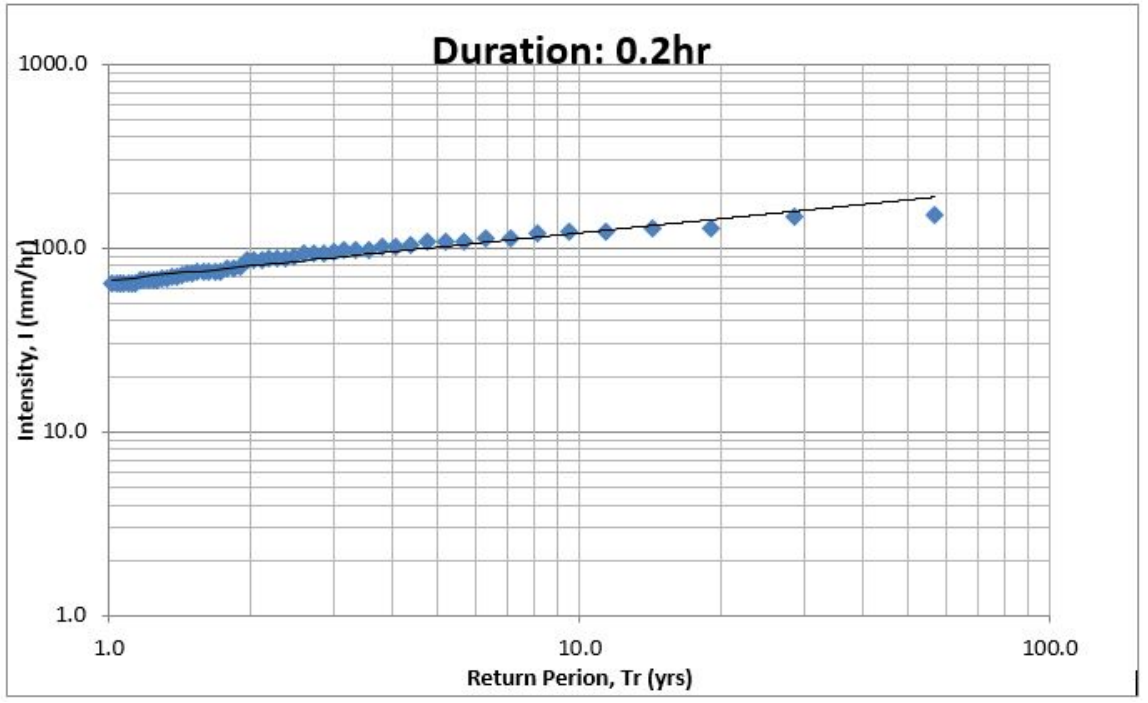

Figure 1: Intensity-Return Period Curves of Abuja for Duration of $0.2 \mathrm{hr}$

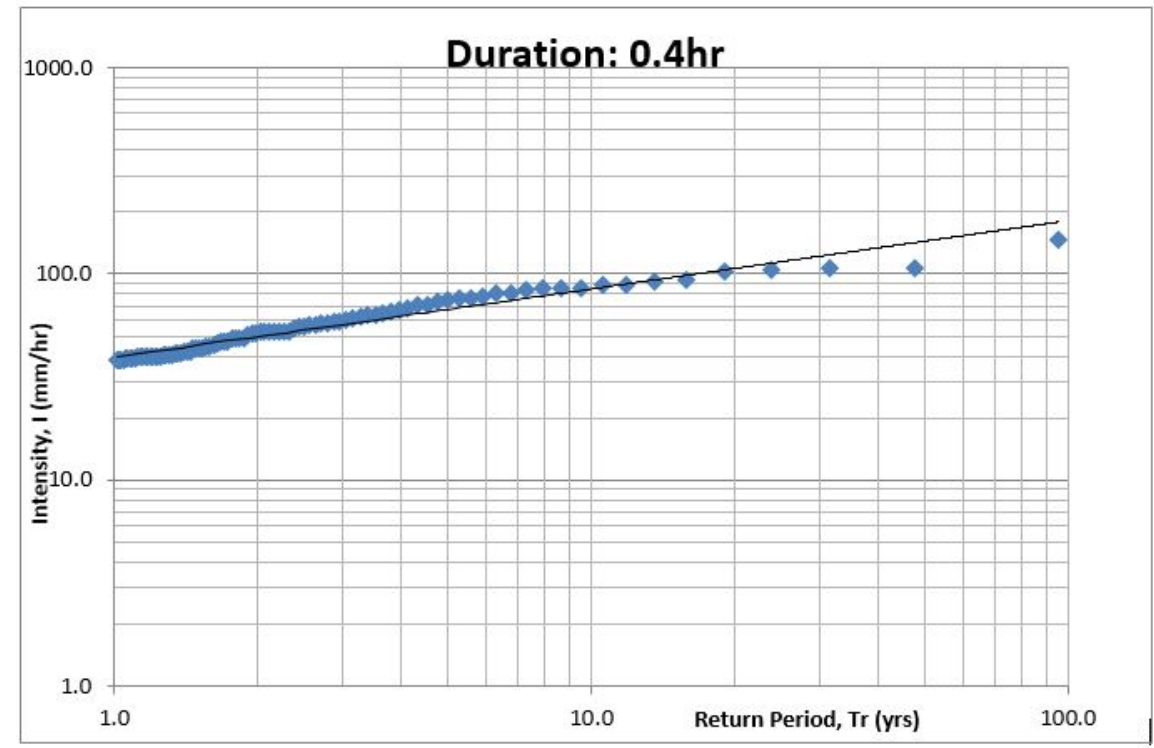

Figure 2: Intensity-Return Period Curves of Abuja for Duration of 0.4hr

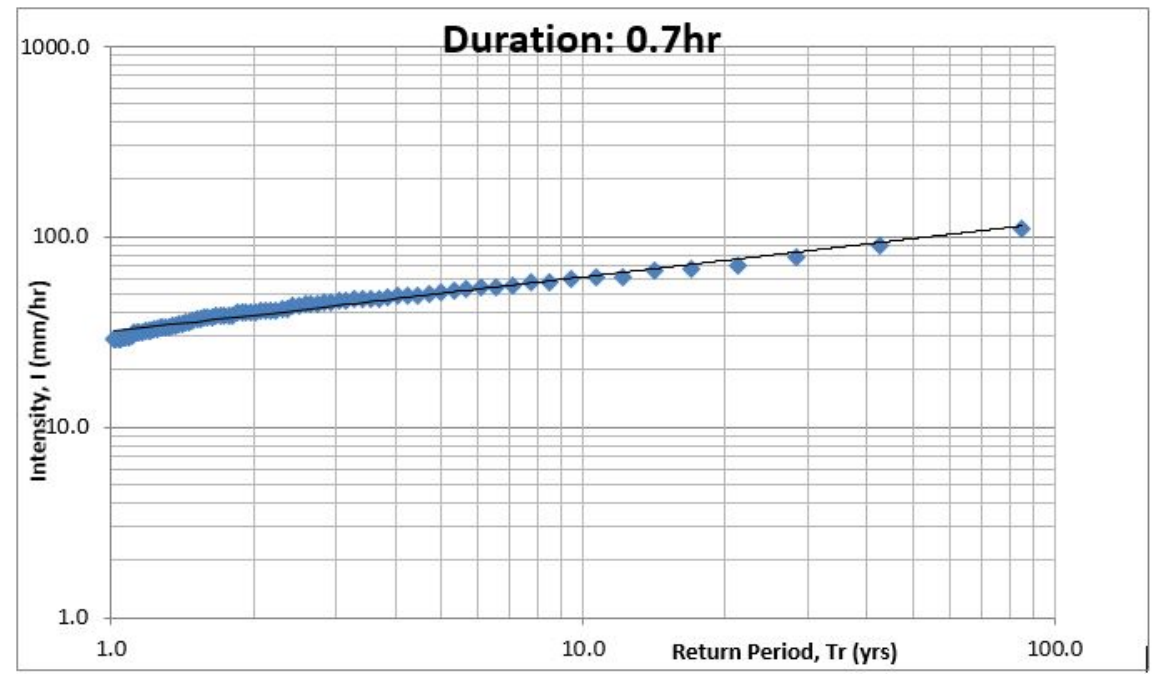

Figure 3: Intensity-Return Period Curves of Abuja for Duration of 0.7hr 
tion of 776,298 , making it one of the 10 most populous cities in Nigeria (internet search: Wikipedia, 22nd March, 2020). According to UN, Abuja grew by $139.7 \%$ between 2000 and 2010 making it fastest growing city in the world (internet search: Wikipedia, 22nd March, 2020). Thus, the need to meet its fast rising infrastructural demand to mitigate anticipated storm disaster [6].

\section{MATERIALS AND METHOD}

A daily rainstorm data collected at $0.2,0.4$, $0.7,1,2,3,6,12$ and $24 \mathrm{hrs}$ durations, spanning through 35 years obtained from NIMET, was adopted for this work.

Using frequency analysis, same numbers of years (n) were used for all durations 0.2 to 24 hours. The data were sorted out from largest to smallest and values that fall below the set lower limit of falls are removed. The designed lower limit of falls for the hours: $0.2,0.4,0.7,1,2$, $3,6,12$, and 24 are $12.7 \mathrm{~mm}, 15.2 \mathrm{~mm}, 20.3 \mathrm{~mm}$, $25.4 \mathrm{~mm}, 25.4 \mathrm{~mm}, 30.8 \mathrm{~mm}, 38.1 \mathrm{~mm}$ and $38.1 \mathrm{~mm}$ respectively [7].

The rainfall depths were then converted to rainfall intensity, using the relationship [8]:

$$
i=\frac{d}{t}
$$

where $i$ is the rainfall intensity $(\mathrm{mm} / \mathrm{hr}), d$ is the rainfall depth (mm) and $t$ is the duration (hr).

The obtained intensity values were then ranked from highest to lowest and assigned value from 1 down to last, $n$. This method is known as Partial Duration Series. The return period, $T$, of the ranked values was then obtained using Weiball's formula [8]:

$$
T_{r}=\frac{n+1}{m}
$$

where, $T_{r}$ is the return period (yrs), $n$ is the total number of the values, $m$ is the rank value of individual intensity.

The calculated intensities were plotted against return period on log-log axes for each duration of $0.2,0.4,0.7,1,2,3,6,12$, and 24 , as shown in Figures 1-9. For each duration, designed intensities of corresponding return period (of $2,5,10$, 25,50 and 100 years) are extracted. Then the extracted intensities are plotted against same durations as a function of return periods on Gumbel Extreme Probability paper to get the final desired Intensity-Duration-Freguency (IDF) curves, as shown in Figure 10. This was achieved conveniently by use of suitable software on personal computer (e.g. Grapher).

The general equation for IDF curve on log-log graph (Horner's formula) is [7]:

$$
I=K T_{r}^{a}(t+c)^{-b}
$$

where $I$ is the rainfall intensity $(\mathrm{mm} / \mathrm{hr}), T_{r}$ is the return period (yrs) and $t$ is the duration (hr). The IDF Relationship can be written in logarithmic form as $[1,2,9]$ :

$$
\log I=(\log k+a \log T)-b \log (t+c)
$$

Equation (4) is in the form of,

$$
y=b+m x \text { (Equation of a straight line }
$$

The lines of equal $T$ are logarithmically spaced at a scalar multiple $(x<1)$ of the logarithmic scale of the paper and are parallel.

\section{RESULTS AND DISCUSSION}

Annual rainstorms of high intensities in Abuja were those of shorter duration $(0.2-1 \mathrm{hr})$. There occurrence in any given year could cause a flash flood especially in flood plain zones of the city, though the magnitude of the storm would vary, with different rainfall intensities [10]. This occurs more frequently, thus, highest return period, $T_{r}$. This trend is confirmed in the literature $[6,11,12]$.

The highest storm recorded throughout the study period was that of $0.2 \mathrm{hr}$, with rainfall intensity of $240 \mathrm{~mm} / \mathrm{hr}$ and its return period is 100 years. The occurrence of this kind of storm can lead to heavy flash flood and torrential overland flow, rapidly increasing the volume of River Niger and its tributaries [11].

The low range of storm occurrences in Abuja $(6-24 \mathrm{hr})$ had the lowest intensity, as could be presumed rightly, highest of them been that of $6 \mathrm{hrs}$, with intensity of $17 \mathrm{~mm} / \mathrm{hr}$ of return period of 100years; the lowest of all the record is that of $24 \mathrm{hr}$ duration corresponding to $2.2 \mathrm{~mm} / \mathrm{hr}$, that was likely returned annually. The intensities of these rainstorms might not be able to contribute significantly to flood occurrence in Abuja, compared to the higher intensities [13]. Thus, by this analysis, lager hydrological structures like dams and bridges, etc., are designed against higher return periods, while small structures like culvert and drainages, etc., are designed for lower return periods.

From the IDF curves, it can be observed that rainfall intensity decreases with length of time, i.e., higher intensity of rainfall in a shorter duration than in a longer duration. This is a normal rainfall pattern behaviour. For rainfall durations less than one hour, (i.e., $\mathrm{t}<1$ ), the graphs may plot as lightly curved lines, hence the inclusion of the constant c in Eq. (3) to enable them plot approximately as straight lines. If the lines do plot sufficiently straight to start with, the value of $c$ is zero [7].

Note that, constants $k, a, b$ and $c$, are derived from the IDF curve and dependant on the condition and location of the rainfall and on the accuracy of the curve [7]:

- $k$ : determines the vertical position of the return period lines as a set on the curve. It is defined as the instantaneous rainfall (i.e., flash storm of 1 minute duration and 1 year return period).

- $a$ : spacing of the curves for various recurrent intervals of $T$ 


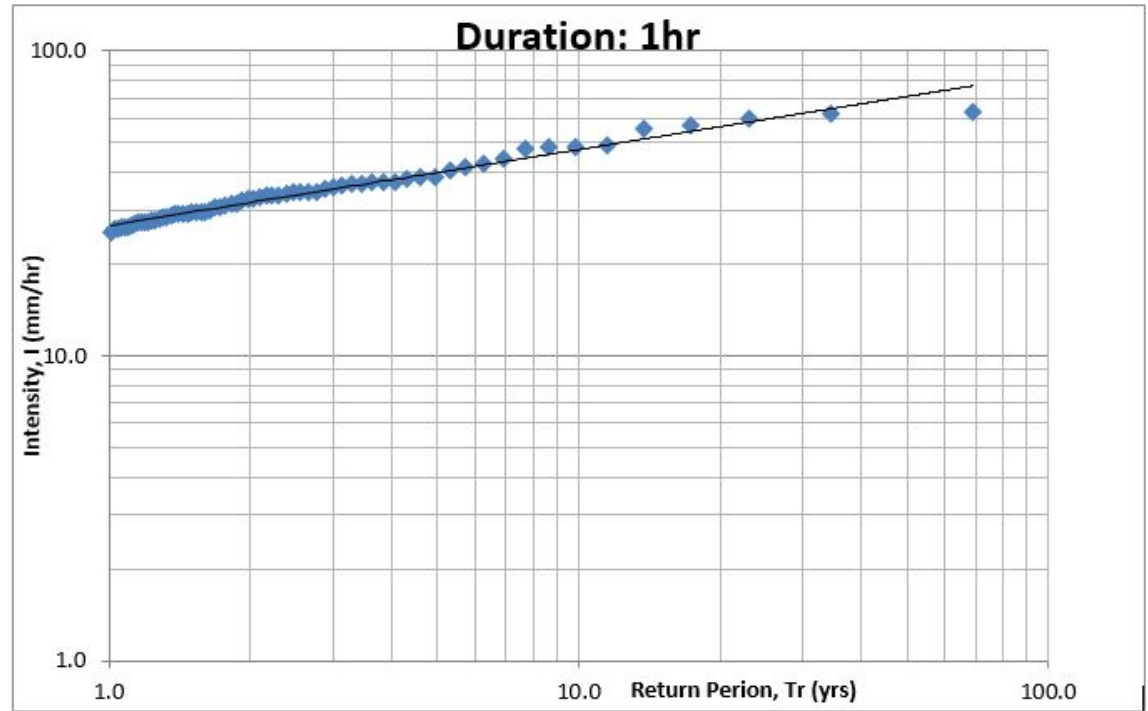

Figure 4: Intensity-Return Period Curves of Abuja for Duration of $1 \mathrm{hr}$

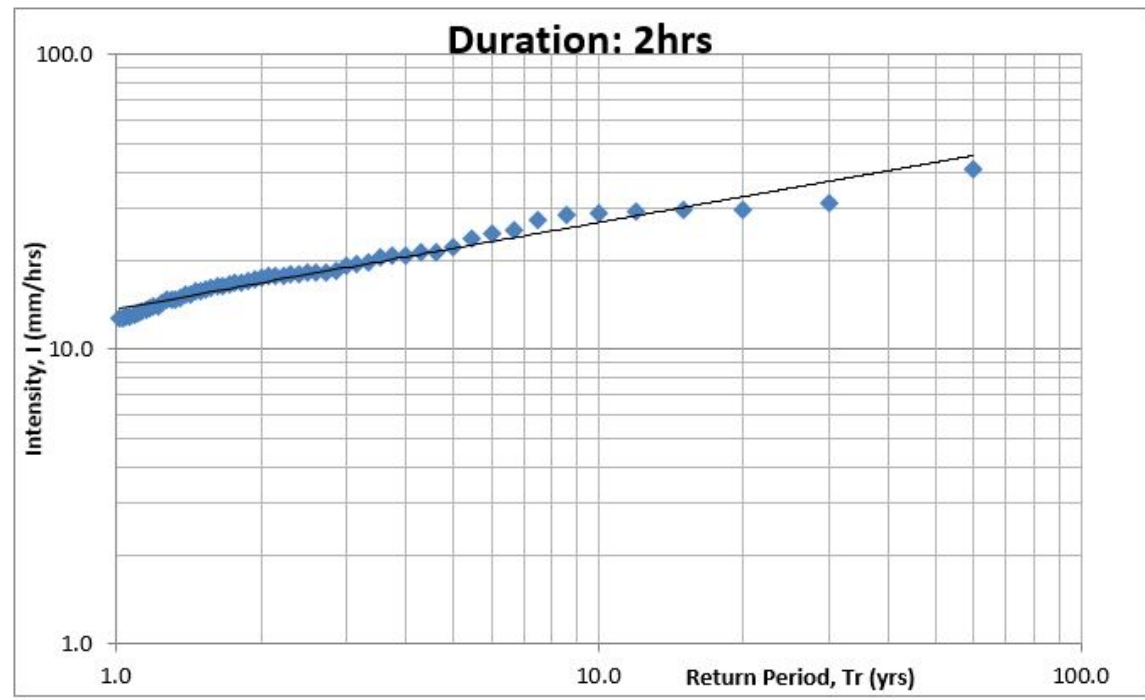

Figure 5: Intensity-Return Period Curves of Abuja for Duration of 2hrs

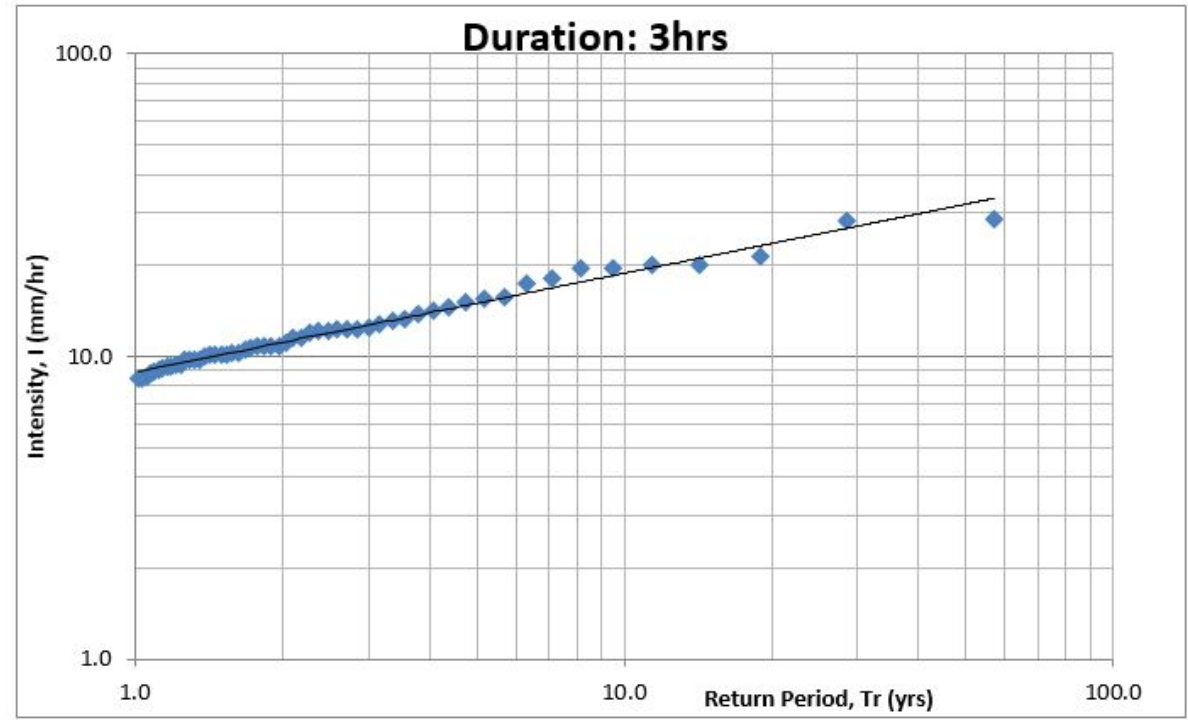

Figure 6: Intensity-Return Period Curves of Abuja for Duration of 3hrs 


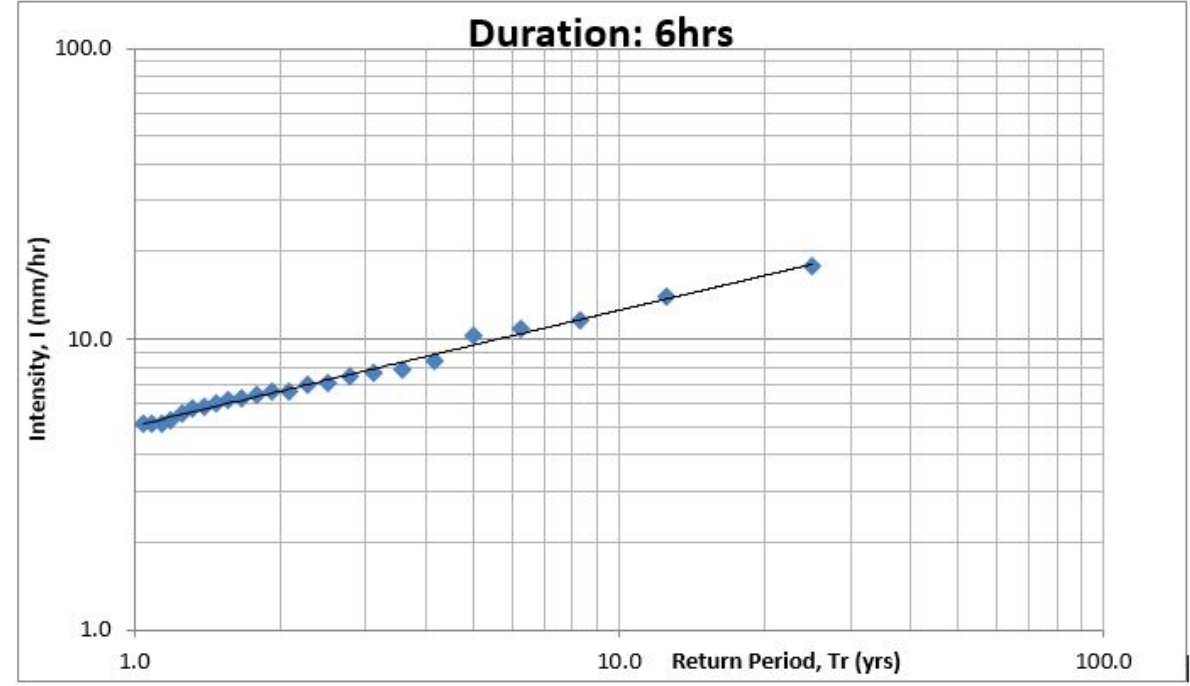

Figure 7: Intensity-Return Period Curves of Abuja for Duration of 6hrs

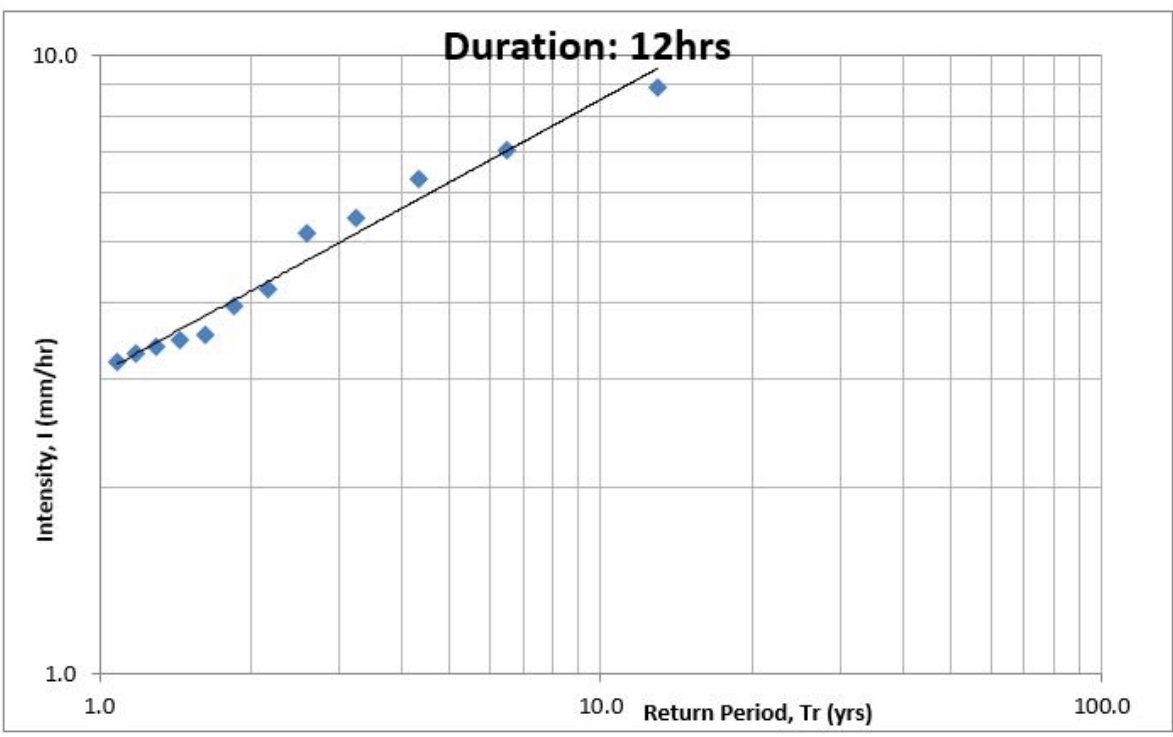

Figure 8: Intensity-Return Period Curves of Abuja for Duration of 12hrs

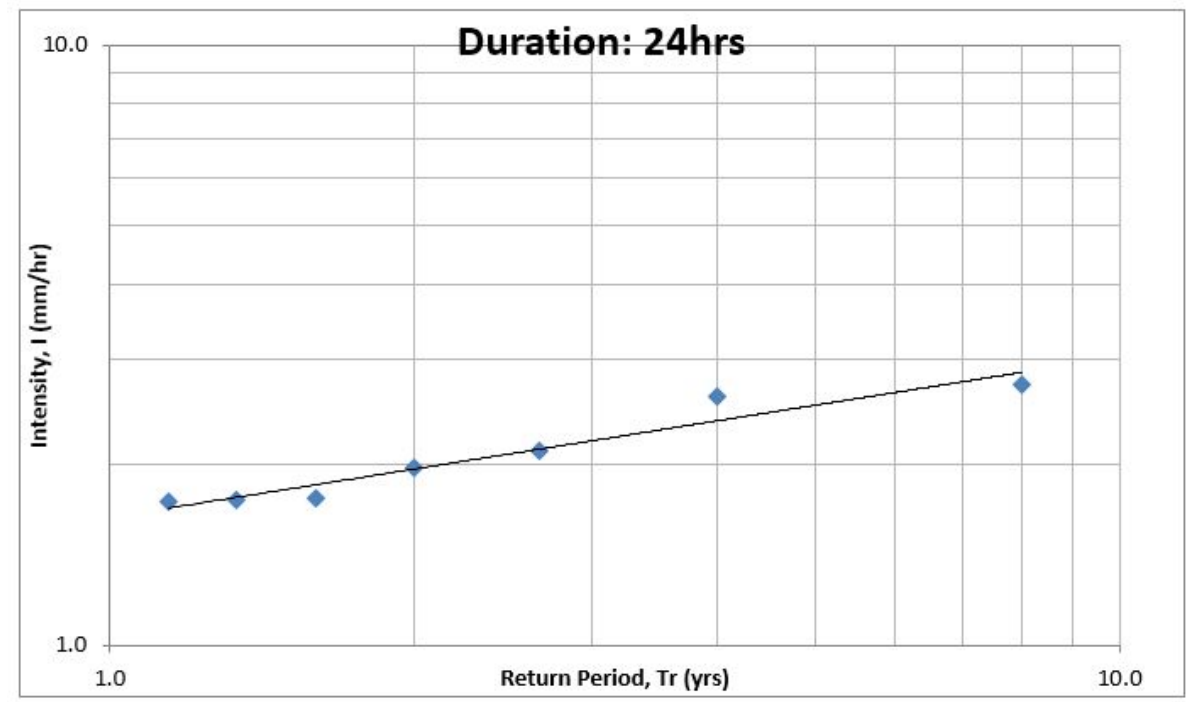

Figure 9: Intensity-Return Period Curves of Abuja for Duration of 24hrs 


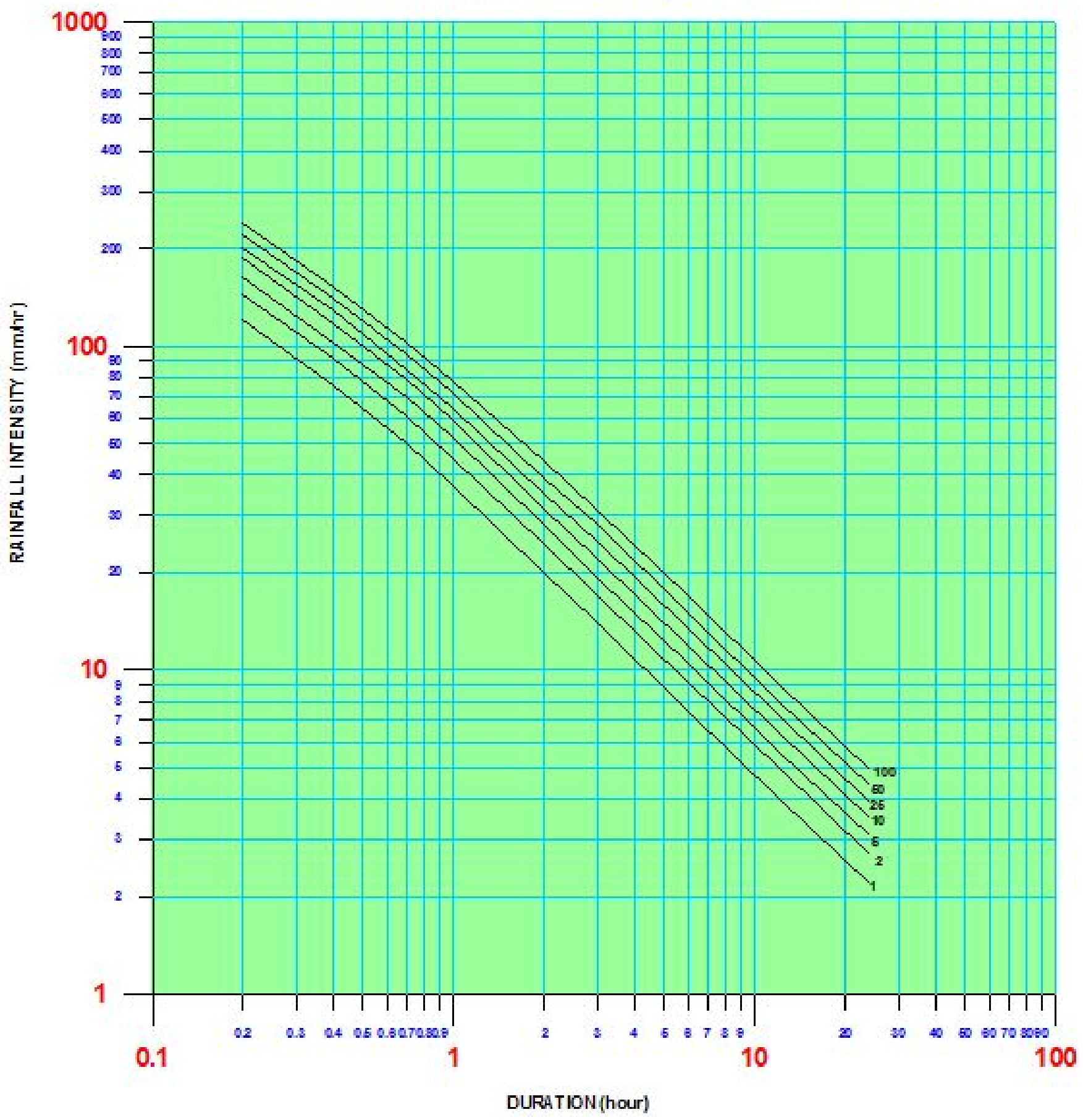

Figure 10: Intensity-Duration-Frequency Curves for Abuja 
- $b$ : negative slope of the straight path of a curve, i.e., $=\frac{\Delta \log i}{\Delta \log (t+c)}$

- $c$ : takes care of the straightness of the curve; if the curve readily plots straight, as in short duration rainfall (i.e., $t 1$ ), $c=0$. But Nigeria rainfall pattern starts with high intensity [14], hence, $c$ is close to 0 , this ensure the curve sufficiently plot straight.

From the IDF curve of Fig. 10, the following constants were obtained thus:

$K=37, a=0.17, b=0.88, c=0.07$

Inputting these values in the Eq. (3) above gives,

$$
I=37 T_{r}^{0.2}(t+0.1)^{-0.9}
$$

This represents the mathematical model equation of Abuja IDF curve, that defines Abuja rainfall pattern. From the model equation, rainfall intensity of any location in Abuja can be obtained if the return period and storm duration are known, and vice versa.

The Eq. (6) above is a mathematical representation of the IDF curve for Abuja, specifically.

\section{CONCLUSION}

Based on the result of this study, the following conclusion can be drawn:

1. Rainfall Intensity-Duration-Frequency (IDF) mathematical model has been developed, using 35 years historic record of Abuja city.

2. The model is an empirical quotient-power type equation, with 4 regional constants $(a, b$, $c$ and $k$ ), that is, rainfall intensity as a function of duration (mins) of $(0.2,0.4,0.7,1,2$, $3,6,12,24 \mathrm{hrs})$ and return period, $T_{r}$, of $(2,5$, $10,25,50,100$ years), adopted for the model calibration.

3. The application of Gombel Extreme Probability graph paper in form of log-log graph paper for a given duration plot intensity as a straight line against return period, with a positive slope in all cases.

4. The model developed has practical utility in design of urban hydrologic structures.

From Fig. 10, rainfall Intensity-DurationFrequency (IDF) curve can be adopted for use to approximately, determine rainfall intensity of the tested area and Abuja generally, if the rainfall duration and frequency (return period) are known, etc, for hydraulic structures design purposes.

\section{References}

[1] I. Nwaogazie and M. C. Ekwueme, "Rainfall intensity-duration (idf) models for uyo city, nigeria," International Journal of Hydrology, vol. 1, no. 3, pp. 63-66, 2017.
[2] F. Olivera and D. Maidment, "Develop basic information to be used for developing a plan to monitor performance of materials," Centre for Transportation Research, Bureau of Engineering Research, University of Texas, Austin, Tech. Rep., 1999, gIS-Based System of Hydrologic and Hydraulic Applications for Highway Engineering.

[3] S. Akpan and B. Okoro, "Development of IntensityDuration-Frequency Models for Calabar City, SouthSouth, Nigeria," American Journal of Engineering Research, vol. 2, no. 6, pp. 19-24, 2013.

[4] R. Antigha and N. Ogarekpe, "Development of Intensity Duration Frequency Curves for Calabar Metropolis, South-South, Nigeria," International Journal of Engineering \& Sciences, vol. 2, no. 3, pp. 39-42, 2013.

[5] Handbook of Hydrology. USA: McGraw Hill Inc., 1993.

[6] Wikipedia. (2019) Abuja City. [Online]. Available: https://en.m.wikipedia.org

[7] NIMET. (2019) Drought and flood monitoring bulletin. [Online]. Available: www.nimet.gov.ng

[8] Applied Hydrology. Singapore: McGraw Hill Book Company, 1988.

[9] M. M. Rasel and M. Islam, "Generation of Rainfall Intensity-Duration-Frequency Relationship for NorthWestern Region in Bangladesh," IOSR Journal of Environmental Science, Toxicology \& Food Technology, vol. 9, no. 9, pp. 41-47, 2015.

[10] N. I. Obot, M. Chendo, S. Udo, and I. Ewona, "Evaluation of Rainfall Trends in Nigeria for 30years (19782007)," International Journal of the Physical Sciences, vol. 5, no. 14, pp. 2217-2222, 2010.

[11] F. Adewale and A. Isaac, "Intensity, Duration and Frequency of Rainstorms in Lokoja," Science World Journal, vol. 12 , no. 2 , pp. $36-40,2017$.

[12] I. L. Nwaogazie and S. C. Okonkwo, "Rainfall-IntensityDuration-Frequency Modeling and Comparative Analysis of Developed models for Abakiliki, Ebonyi State Nigeria," International Journal of Trend in Research and Development, vol. 4, no. 2, pp. 45-53, 2017.

[13] A. T. R., "Frequency Analysis of Maximum Daily Rainfall for Selected Towns in North-Central Nigeria," $\mathrm{Hy}$ drology and Water Resource, vol. 9, no. 3, pp. 776-783, 2013.

[14] B. F. Sule and K. Ige, "Synthesis of Isopluvial Maps for Nigeria Using IDF Equations Derived from Daily Rainfall Data," Journal of Scientific \& Engineering Research, vol. 3, no. 3, pp. 505-514, 2016. 